\title{
Optimal beam quality selection based on contrast-to-noise ratio and mean glandular dose in digital mammography
}

Type: Article

Abstract:

The performance of a digital mammography system (Siemens Mammomat Novation) using different target/filter combinations and tube voltage has been assessed. The objective of this study is to optimize beam quality selection based on contrast-to-noise ratio (CNR) and mean glandular dose (MGD). Three composition of breast were studied with composition of glandular/adipose of 30/70, 50/50, and 70/30. CNR was measured using 2, 4 and $6 \mathrm{~cm}$-thick simulated breast phantoms with an aluminium sheet of 0.1 $\mathrm{mm}$ thickness placed on top of the phantom. Three target/filter combinations, namely molybdenum/molybdenum (Mo/Mo), molybdenum/rhodium (Mo/Rh) and tungsten/rhodium (W/Rh) with various tube voltage and mAs were tested. MGD was measured for each exposure. For 50/50 breast composition, Mo/Rh combination with tube voltage $26 \mathrm{kVp}$ is optimal for $2 \mathrm{~cm}$-thick breast. W/Rh combination with tube voltage 27 and $28 \mathrm{kVp}$ are optimal for 4 and $6 \mathrm{~cm}$-thick breast, respectively. For both $30 / 70$ and $70 / 30$ breast composition, W/Rh combination is optimal with tube voltage 25 , 26 and $27 \mathrm{kVp}$, respectively. From our study it was shown that there are potential of dose reduction up to $11 \%$ for a set CNR of 3.0 by using beam quality other than that are determined by AEC selection. Under the constraint of lowest MGD, for a particular breast composition, calcification detection is optimized by using a softer X-ray beam for thin breast and harder X-ray beam for thick breast. These experimental results also indicate that for breast with high fibroglandular tissues (70/30), the use of higher beam quality does not always increase calcification detection due to additional structured noise caused by the fibroglandular tissues itself.

\begin{tabular}{|c|c|}
\hline Author & $\begin{array}{l}\text { - Aminah, M. } \\
\text { - Ng, K. H. } \\
\text { - Abdullah, B. J. J. } \\
\text { - Jamal, N. }\end{array}$ \\
\hline Source & Australasian Physical \& Engineering Sciences in Medicine \\
\hline ISSN & 0158-9938 \\
\hline $\mathrm{DOI}$ & $10.1007 / \mathrm{s} 13246-010-0035-3$ \\
\hline Volume (Issue) & $33(4)$ \\
\hline Page & $329-334$ \\
\hline Year & 2010 \\
\hline
\end{tabular}

Keyword:

Digital mammography, Optimization, Mean glandular dose, Contrast-to-noise ratio, Optimization, system

Please Cite As: 
AMINAH, M., NG, K. H., ABDULLAH, B. J. J. \& JAMAL, N. 2010. Optimal beam quality selection based on contrast-to-noise ratio and mean glandular dose in digital mammography. Australasian Physical \& Engineering Sciences in Medicine, 33, 329-334.

URL:

- http://apps.webofknowledge.com search via Accession No >> 000288432000005

- http://scienceindex.com/stories/1149935/Optimal beam quality selection based on contrasttonoise ratio and mean glandular dose in digital mammography html\#.UHtcr8XMhoc

- http://www.bioportfolio.com/resources/pmarticle/100517/Optimal-Beam-QualitySelection-Based-On-Contrast-to-noise-Ratio-And-Mean.html

- http://www.springerlink.com/content/461p3023266l3633/ 